\title{
Empreendedores nas regiões oeste e norte da capital de São Paulo: organizando o caos
}

\author{
Kleber Markus ${ }^{1}$ (In memoriam) \\ Marcos Antonio Novaes ${ }^{2}$
}

\begin{abstract}
Resumo
No Brasil, os microempreendimentos representam de 5,6 a 6 milhões de empresas, segundo pesquisas do SEBRAE (2010). Cumprem um papel importante para o PIB (Produto Interno Bruto) nacional. As pesquisas de mortalidade desses negócios mostram que cerca de $75 \%$ não conseguem permanecer no mercado além dos seis meses iniciais. A abertura desses pequenos negócios decorre, em muitos casos, da necessidade oriunda do desemprego. O empreendedor, anteriormente registrado, pode usar sua indenização e o Fundo de Garantia do Tempo de Serviço para iniciar um novo empreendimento. Geralmente, de acordo com as pesquisas, tais negócios não têm um suporte adequado nem constituem um plano de negócios, diferente de outros países como Estados Unidos e Canadá, em que isso é condição básica para o início de um empreendimento. As pesquisas mostram que o cenário para os microempreendedores é de dificuldades. Por outro lado, contrariando as pesquisas de mortalidade (SEBRAE, 2010), existem pequenos negócios que sobrevivem ao longo do tempo, passando à margem de toda a oscilação do mercado, tanto interno quanto externo. O presente trabalho analisará seis empresas das regiões norte e oeste de São Paulo, capital, com pequenos negócios que estão estabilizados no mercado, nas proximidades dos terminais de Santana e Butantã. Além disso, mostrará quais as dificuldades transpostas por esses empreendedores para dar longevidade a seus negócios.
\end{abstract}

Palavras-chave: Micros e pequenos empreendedores. Pesquisas. SEBRAE.

\begin{abstract}
According to the SEBRAE (2010) research in Brazil, microenterprise represent 5,6 to 6 million of company. Meet an important role for the National GDP (PIB). The mortality of these business surveys show that about $75 \%$ fail to remain on the market beyond the initial six months. Opening these small businesses is due in many cases, the need arising from unemployment. The previously registered entrepreneur can use your compensation and the Guarantee Fund for Time of Service to start a new enterprise. Most often, these businesses do not have adequate support or constitute a business plan, differently of other countries like the United States and Canada, where is a basic condition for the beginning of a project. Moreover, contrary to the research of mortality (SEBRAE, 2010), there are small businesses that survive over time, from the sidelines of all the oscillation of the market, both internal and external. This paper will examine six micro enterprises of the northern and western regions of São Paulo, capital, and with small businesses that are more than five years in the market and formed near the subway terminals, Santana and Butantã. Also, show what difficulties transposed by these entrepreneurs to give longevity to yours business.
\end{abstract}

\footnotetext{
1 Pós-doutor - Sorbonne, Doutor e mestre - USP. Foi prof. titular da Universidade Metodista de São Paulo - Stricto Sensu - PPGA.

${ }^{2}$ Mestre em Administração pela Universidade Metodista de São Paulo. marcos.novaes@uol.com.br
} 
KEY WORDS: Micro and small achievers. Research. SEBRAE.

\section{INTRODUÇÃO}

O empreendedorismo começou a surgir no Brasil a partir das tentativas de Portugal de tornar a colônia habitável. Com a grande distância da metrópole, pequenos empreendimentos foram estabelecidos para sustentar a colônia com artigos dos quais necessitava. Além disso, havia a intenção de se tomar posse da nova terra, antes que navegadores de outras nações o fizessem.

A nova terra necessitava de tudo. As viagens transoceânicas eram longas, tornando dificultoso prover a colônia daquilo que esta precisava. Os pequenos empreendimentos surgiram, assim, pela necessidade do que a nova terra tinha. Com a indústria extrativista e com a cana de açúcar, vários engenhos foram criados no nordeste do Brasil. Nesse momento da história, a colônia era habitada nas regiões litorâneas, onde portos foram criados para receber as caravelas e para dar a saída de mercadorias. Os primeiros engenhos foram criados perto de rios, procurando usar as águas para auxiliar as moendas e também o transporte, conforme discorrem Souza et al. (2007). Tratava-se basicamente de pequenos fortes com ampla segurança, para evitar o contato violento com os indígenas que habitavam a terra, segundo nos relata Muniz (1982 apud SOUZA et al., 2007). À medida que os colonizadores começaram a adentrar a floresta, novos empreendimentos e empreendedores começaram a surgir, tais como as pousadas e os tropeiros. Os colonizadores precisavam de locais para descanso e alimentação, o que deu ensejo ao surgimento desses locais de parada (PASSETI, 1999).

A produção de alimentos e de bebidas na colônia acabou contrariando a coroa portuguesa. Se os nativos produzissem aqui, não precisariam comprar da coroa. Nesse momento, pequenos empreendedores ocupavam-se do cultivo de fumo e comerciavam escravos. Com a descoberta do ouro em Minas Gerais, houve um grande afluxo de pessoas (PASSETI, 1999).

Para esse abastecimento surgiram os tropeiros, que levavam víveres em lombo de mulas ou de escravos, provendo o interior do país. O tropeiro pode ser considerado um microempreendedor autônomo, pois trabalhava e dirigia seu negócio de transportes sozinho. Essa fase da história do Brasil facilitou o surgimento de pequenos empreendimentos que supriam tudo aquilo que era necessário para a sobrevivência da província. Com a imigração, 
outros povos passaram a viver aqui, entre eles os sírios e os libaneses, que criam a figura do mascate, aquela figura que viajava por todos os cantos do país comerciando produtos de pequena monta. A chegada da família real ao Rio de Janeiro, por sua vez, também fomentou o crescimento da cidade. Tem início, assim, o trabalho assalariado, que acaba expandido a atividade econômica, segundo Fulkelman et al. (2003).

Apesar de toda a ajuda prestada pelos pequenos empreendedores para o crescimento do Brasil, somente muito mais tarde, na Constituição Federal de 1988, é que eles tiveram uma classificação como tal. Nesse momento são definidos como micro e pequenos empresários, tendo uma classificação específica nas atividades econômicas e financeiras do governo e na legislação federal (AGÊNCIA BRASIL).

A preocupação do governo para com os pequenos empreendimentos forçou a criação do CEBRAE (Centro Brasileiro de Assistencial Gerencial à Pequena e Média Empresa) que, funcionando atrelado aos Ministérios, principalmente ao do Planejamento, não conseguiu obter os resultados esperados, sendo substituído em 1990 pelo SEBRAE (Serviço Brasileiro de Apoio às Micro e Pequenas Empresas), serviço autônomo, com capital próprio, que procura gerenciar, treinar, capacitar, assessorar e cuidar de todos aqueles pretendentes a empresários. Outro fato memorável foi a promulgação, em 2006, do Estatuto da Micro e Pequena Empresa e da Empresa de Pequeno Porte.

Tudo seria "maravilhoso" não fosse a dificuldade encontrada na hora de se abrir e fechar um pequeno negócio. O pequeno empreendedor tem de contratar uma empresa de contabilidade para fazer frente à burocracia estatal, tal a quantidade de autarquias, documentos e prazos que deverá cumprir para se tornar empresário (SEBRAE, 2011).

Para mostrar as dificuldades enfrentadas e vencidas pelo empreendedor, foi aplicada uma pesquisa qualitativa, com entrevistas pessoais em profundidade, a partir de uma amostra não probabilística, por cota, com seis empresas que, conforme consulta prévia, estão no mercado há mais de cinco anos nas regiões norte e oeste de São Paulo, grandes centros empreendedores.

Visto o cenário, podemos então definir como problema: Quais as atitudes e ações dos empreendedores para ultrapassarem as dificuldades iniciais e estarem ativos com mais de cinco anos de existência?

\section{REFERENCIAL TEÓRICO}


Para o desenvolvimento deste, foi realizado um estudo exploratório que traz informações legais acerca da abertura e do enquadramento das micros e pequenas empresas.

A começar, o governo brasileiro traz uma série de incentivos para estimular o crescimento de microempresas e de empresas de pequeno porte, tendo estas um tratamento especial, por meio de leis, como mostra abaixo o artigo 179 da constituição brasileira, promulgada em 1988.

Artigo 179. A União, os Estados, O Distrito Federal e os Municípios dispensarão às microempresas e às empresas de pequeno porte, assim definidas em lei, tratamento jurídico diferenciado, visando a incentivá-las pela simplificação de suas obrigações administrativas, tributárias, previdenciárias e creditícias, ou pela eliminação ou redução destas por meio de lei. (CALDAS, 1989)

Para formalizar e dar aspectos jurídicos aos microempreendimentos, foi promulgada a Lei Complementar $n^{\circ}$ 123, de 14/12/2006, que instituiu o Estatuto Nacional da Microempresa e da Empresa de Pequeno Porte:

Art. $3^{\circ}$ : Para os efeitos desta Lei Complementar consideram-se microempresas ou empresas de pequeno porte a sociedade empresária, a sociedade simples e o empresário a que se refere o art. 966 da Lei $n^{\circ} 10.406$ de 10 de janeiro de 2002, devidamente registrados no Registro de Empresas Mercantis ou no Registro Civil de Pessoas Jurídicas, conforme o caso, desde que:

I- no caso das microempresas, o empresário, a pessoa jurídica, ou a ela equiparada, aufira, em cada ano-calendário, receita bruta igual ou inferior a $\mathrm{R} \$ 240.000,00$ (duzentos e quarenta mil reais);

II- no caso de empresas de pequeno porte, o empresário, a pessoa jurídica, ou a ela equiparada, aufira, em cada ano calendário, receita bruta superior a $\mathrm{R} \$$ $240.000,00$ (duzentos e quarenta mil reais) e igual ou inferior a $\mathrm{R} \$ 2.400 .000,00$ (dois milhões e quatrocentos mil reais). (SANTOS et al., 2012)

Além das microempresas e das empresas de pequeno porte, há os empreendedores individuais. Eles também têm incentivos do governo. Inclusive, o limite anual do simples para o empreendedor individual era de $\mathrm{R} \$ 36$ mil até o ano de 2011, limite este que teve um aumento de quase $67 \%$ a partir de 2012, ficando em R \$ 60 mil (SANTOS et al., 2012). Acima deste valor, o empreendedor individual muda de enquadramento, passando a ser microempresa.

Tendo em vista o enquadramento na legislação, no sentido de serem cobrados impostos e taxas, a Receita Federal criou uma tabela de classificação, conforme demonstrada na tabela abaixo. 
Tabela 1 - Classificação das micros e pequenas empresas de acordo com a receita anual a partir de 2012

\begin{tabular}{l|c}
\hline \multicolumn{1}{c|}{ Porte } & $\begin{array}{c}\text { Simples Nacional } \\
\text { Faturamento anual }\end{array}$ \\
\hline Microempresas & Até $\mathrm{R} \$ 360.000,00$ \\
\hline Pequenas empresas - EPP & Acima de $\mathrm{R} \$ 360.000,00$ \\
& e até $\mathrm{R} \$ 3,6$ milhões \\
\hline
\end{tabular}

Fonte: Simples Nacional, Lei Complementar Federal no 139 de 10/11/11 (SANTOS et al., 2012).

Conforme o número de empregados, as empresas podem ser classificadas da seguinte forma:

Tabela 2 - Classificação das empresas segundo o número de empregados

\begin{tabular}{l|l|l}
\hline \multicolumn{1}{c|}{ Porte/setor } & \multicolumn{1}{c}{ Indústria } & \multicolumn{1}{c}{ Comércio e serviços } \\
\hline Microempresas & Até 19 empregados & Até 9 empregados \\
\hline Empresas de pequeno porte & De 20 a 99 & De 10 a 49 \\
\hline Médias & De 100 a 499 & De 50 a 99 \\
\hline Grandes & 500 ou mais & 100 ou mais \\
\hline
\end{tabular}

Fonte: SEBRAE (2011).

\subsection{Abertura de um negócio}

Segundo dados de agosto de 2010 extraídos da Pesquisa de Mortalidade das Empresas elaborada pelo SEBRAE-SP, cerca de $27 \%$ das empresas paulistas fecham em seu primeiro ano de atividade. Entre as principais causas dessas falências, de acordo com o estudo, estão a gestão ineficiente do negócio e a falta de planejamento.

Dessa forma, para que um empreendimento alinhe seus objetivos e mantenha-se sempre competitivo no mercado, é necessário que ele tenha real controle sobre seus recursos financeiros (SEBRAE, 2010).

Mas, antes mesmo de o futuro empreendedor tornar-se empresário, ele vai tomar conhecimento da burocracia governamental para abertura de novos negócios. Entre elas estão (podem variar conforme a unidade da federação, abaixo é referente a São Paulo): 
1. Registro da empresa na Junta Comercial do Estado de São Paulo, do contrato social, para ter os direitos e deveres assegurados mediante o registro.

2. Inscrição na Receita Federal, para obtenção do CNPJ - Cadastro Nacional de Pessoa Jurídica.

3. Inscrição na Prefeitura Municipal de São Paulo, para obtenção do cadastro de contribuinte mobiliário.

4. Registro da Previdência Social para inscrição da empresa no INSS, (Instituto Nacional de Seguridade Social).

5. Companhia de Saneamento Ambiental Ciência e Tecnologia (CETESB) para os empreendimentos que realizarem atividades poluidoras.

6. Registro no sindicato da categoria.

7. Vigilância Sanitária, somente em atividades nas quais se manipulem alimentos, produtos farmacêuticos e odontológicos.

8. Registro na Secretaria da Fazenda do Estado, somente se a empresa for contribuinte do ICMS (Imposto sobre Circulação de Mercadoria e Serviços) empresas mercantis e prestadoras de serviços de telecomunicação e transportes. (Adaptado de SEBRAE-RS, acessado em 2014)

\subsection{Análise de pesquisas secundárias}

Diferentemente das empresas maiores, que possuem uma estrutura complexa e atuante, nos pequenos negócios, mesmo que haja uma hierarquia definida, com colaboradores exercendo cargos de supervisão, "a voz do dono" é quem comanda o empreendimento. De acordo com pesquisas do SEBRAE e, conforme já apontado, o pequeno empreendimento é criado a partir da necessidade do empreendedor por ocasião de perda do emprego.

De acordo com o GEM - Global Entrepreneurship Monitor (LIMA, 2010), o Brasil estava, na ocasião em que esta pesquisa foi realizada, em $15^{\circ}$ lugar em oportunidade e em $4^{\circ}$ lugar em necessidade. Isso quer dizer que o empreendedor de um novo negócio geralmente usa sua capacidade adquirida em outras empresas e abre seu próprio empreendimento, sem realizar um plano de negócios.

Para gerenciá-lo, não faz cursos de capacitação e não tem sócios. Sua experiência vai sendo adquirida ao mesmo tempo em que procura fazer o negócio prosperar. Nesse processo, cuida sozinho das decisões administrativas, financeiras, de produção, contábeis, compras, vendas, tributárias, trabalhistas, para citar somente algumas. Empiricamente, vai adquirindo ou não qualificação, podendo fazer seu negócio participar das pesquisas consolidadas, com o fechamento da empresa em seus primeiros anos de funcionamento.

Para abrir seu empreendimento, recebe ajuda de um escritório de contabilidade, que vai assessorando o negócio no sentido de contribuir nos cálculos de impostos, taxas e na emissão de folhas de pagamento com seus respectivos recibos. Havendo dispensa de algum colaborador, faz o pagamento e a homologação, se houver necessidade. A participação é restrita. No final do exercício, elabora os demonstrativos contábeis e entrega a declaração do 
Imposto de Renda e outros tais como RAIS (Relação Anual de Informações Sociais) nos órgãos competentes (SANTOS et al., 2012).

No dia a dia da empresa, o contador não participa da tomada de decisões nem ajuda na execução de planejamentos, que ficam restritas ao proprietário. Na maioria das vezes, este contador também é um microempresário que tem de cuidar de seu próprio negócio, dos clientes e garantir sua própria sobrevivência. Para o pequeno empresário, o ideal seria conseguir um sócio, com o qual pudesse dividir tarefas e responsabilidades, ficando mais fácil o processo de gerir e administrar. Na administração das finanças, conforme relatam as pesquisas, o gestor tem dificuldade nesse gerenciamento. Confunde contas pessoais com contas da empresa, acrescentando assim um complicador na administração das despesas e na consequente formação de preço final de seus produtos (YAZIGI, 2001).

Por ocasião da entrega do Demonstrativo de Resultados do Exercício, o proprietário não faz uma leitura para compreender o que aconteceu no ano e para definir o planejamento para o ano seguinte, aceita as considerações do contador e arquiva o livro (SANTOS et al., 2012).

Mesmo com todos esses problemas de gestão no micro e pequeno negócio, existem empresas que passam do período de crise dos dois anos e se consolidam no mercado, ganhando estabilidade. Com isso, acabam provocando o surgimento de novos negócios, que se instaura por comparação, ou seja, "se aquele negócio prosperou e deu certo, o que pretendo ter é igual e também dará”, começando aí um novo ciclo.

As características dos empresários com registro de empresa na JUCESP (Junta Comercial do Estado de São Paulo) 2007, segundo o SEBRAE (2010):

$83 \%$ tinham ensino médio completo.

$78 \%$ abriram por "oportunidade".

64\% são do gênero masculino.

$62 \%$ afirmam ter tido experiência ou conhecimento anterior no ramo.

$67 \%$ têm familiares ou amigos donos de empresa.

37 anos é a média de idade de quem abriu a empresa.

$32 \%$ estavam ocupados como empregados de empresa privada antes da abertura da empresa.

Como mostra o Global Entrepreneurship Monitor (LIMA, 2010), em pesquisas de MPEs em diversos países, constatou-se que o Brasil tinha a maior taxa de empreendedorismo por necessidade. Isso quer dizer que o empregado perde seu posto de trabalho e que, com o 
montante recebido das indenizações trabalhistas, abre seu próprio negócio, legalizado ou não, usando sua expertise em determinado ramo da administração, vendas, produção ou marketing.

Esse ponto foi considerado negativo em detrimento de empresas criadas por conta de uma oportunidade de negócio ou por um plano estruturado de negócio, cujas chances de sobrevivência são muito maiores.

No ambiente atual de grande terceirização e globalização, as micros e pequenas empresas têm no ambiente corporativo de multinacionais ou mesmo das grandes empresas nacionais uma enorme oportunidade de negócios.

Hoje se terceiriza, em alguns casos, as competências essenciais das empresas, que são aquelas que não podem ser copiadas ou terceirizadas (FLEURY, 2003). Pode-se notar que tudo aquilo que gera custo ou não agrega valor ao negócio é terceirizado. Como exemplo disso estão as folhas de pagamento, a alimentação, a logística, a segurança, o recrutamento e a seleção, somente para se falar nos mais óbvios e imediatos.

De acordo com Lima (2010), as estatísticas oficiais referentes à extinção de empresas não expressam a realidade brasileira, pois muitos negócios fecham suas portas sem dar baixa nos registros oficiais ou o próprio empreendedor não finaliza o negócio, contando com a possibilidade de abri-lo novamente num futuro próximo.

Conforme citado em Lima (2010), os empreendedores devem ter uma atenção especial para com o planejamento, no sentido de evitar a insolvência prematura de sua empresa e seu consequente fechamento.

Assim, no planejamento, é imprescindível a elaboração de um plano de negócios, pois depender somente da intuição e da experiência não garante a continuidade do negócio (LIMA, 2010).

\footnotetext{
Plano de negócios é um documento pelo qual o empreendedor formalizará os estudos a respeito de suas ideias, transformando-as em um negócio. É no plano de negócios que estarão registrados o conceito do negócio, os riscos, os concorrentes, o perfil da clientela, as estratégias de marketing, bem como todo o plano financeiro que viabilizará o novo negócio. O plano de negócios é também um ótimo instrumento de apresentação do negócio para o empreendedor que procura sócio ou investidor. (BERNARDI, 2006)
}

Já segundo Terence et al. (2007), pode-se caracterizar planejamento como um processo contínuo que estabelece a interação da empresa com o ambiente, que permite definir seus objetivos e suas potencialidades e que orienta para o melhor aproveitamento dos recursos que utiliza.

O planejamento estratégico apresenta-se como uma ferramenta que orienta os rumos e as ações da organização em seu ambiente interno e externo (TERENCE et al., 2007). 
As MPEs têm suas próprias características, comparando-se com as grandes organizações. Geralmente não possuem organograma, a hierarquia não é rígida, o dono ou o empresário ou ainda o proprietário participa de todas as fases do processo, da compra de insumos e matéria-prima, e até da logística.

A literatura do gênero demonstra que as mesmas ferramentas de gestão usadas nas grandes organizações podem ser adaptadas para as pequenas empresas, como relatam Terence et al. (2007). O problema para sua implantação é a insegurança dos empresários e seu medo de mudanças. O que de certa forma auxilia a eliminação de seus negócios do mercado.

Uma das dificuldades na implementação de um planejamento nas MPEs é a de se obter informações ou mesmo de analisá-las, conforme nos relatam TERENCE et al. (2007). O empresário não tem em sua expertise a função de administrador como ponto forte para sua gestão, pois seu foco está na gestão de sua empresa.

No âmbito empresarial, sempre foi muito difícil encontrar um meio de quantificar percentualmente os objetivos arrolados no planejamento estratégico das empresas.

Para o incremento e uso das ferramentas de grandes empresas, as MPEs teriam de ter necessariamente uma pessoa que seria às vezes administrador, gestor, chefe ou qualquer outro adjetivo do gênero. Sabe-se que, na abertura dos novos negócios, nem sempre os sócios advêm de bancos acadêmicos, de formação ou de algum curso técnico ministrado no SEBRAE para se qualificar tecnicamente no negócio que pretendem iniciar. Ou, menos ainda, teriam eles feito uma pesquisa de campo para saber quais seriam as garantias de que o negócio idealizado teria condições de prosperar e qual o terreno que o novo empreendedor "iria pisar".

Por isso, o dono do negócio ou o gestor das MPEs nem sempre tem a expertise necessária para a adoção de ferramentas de administração, que, certamente, prolongaria a vida dos pequenos negócios.

Na maioria das vezes, segundo as pesquisas do SEBRAE (2010), o gestor das MPEs não tem curso superior, apenas a vontade de fazer a diferença e conduzir seu negócio da melhor forma possível, ainda que constituído por necessidade e não por um plano de negócio bem construído.

Ainda, segundo o SEBRAE (2010), as principais dificuldades enfrentadas pelos empreendedores no primeiro ano de atividade são:

Falta de clientes (20\%).

Falta de capital (21\%).

Administração e planejamento (11\%). 
Burocracia e impostos (7\%).

Mão de obra (5\%).

Concorrência (5\%).

Outras dificuldades (6\%).

Nenhuma (16\%).

Como o empreendedor não tem experiência no negócio e não fez um planejamento antes de iniciá-lo, a falta de cliente é o fator que mais aparece em destaque.

Dado o desconhecimento do negócio, a falta de capital também se faz presente, pois aquele utilizado inicialmente não fez frente aos gastos reais que surgirão no desenvolvimento do negócio. A falta de uma administração eficaz do caixa também é fator de impacto.

Tabela 3 - Comparação entre início e fechamento

\begin{tabular}{l|c|l|c}
\hline DIFICULDADE INICIAL & $\boldsymbol{\%}$ & FECHAMENTO & $\%$ \\
\hline Falta de cliente & 29 & Falta de cliente & 18 \\
\hline Falta de capital & 21 & Falta de capital & 10 \\
\hline Administração/planejamento & 11 & Administração/planejamento & 10 \\
\hline Burocracia/impostos & 7 & & \\
\hline Mão de obra & 5 & & 15 \\
\hline Concorrência & 5 & & 8 \\
\hline Outras & 6 & Outras & 8 \\
\hline Nenhuma & 16 & & 7 \\
\hline & & Perda do cliente único & \\
\hline & & Problemas com sócios & 8 \\
\hline
\end{tabular}

Fonte: Adaptado de SEBRAE (2010) e Santos e Pereira (1995).

Quando se comparam as dificuldades iniciais dos empreendedores com as causas do encerramento dos negócios, verificamos que a falta de clientes corresponde a $18 \%$ dessas causas; falta de capital corresponde a 10\%; e problemas com administração e planejamento do 
negócio outros $10 \%$. Assim, se a empresa foi mal estruturada no início, esta falta de estrutura também poderá ocasionar seu fechamento. Um dos motivos relevantes para isso é a figura do cliente único. Normalmente, as prestadoras de serviço correm esse risco. Trabalham para um cliente grande e, de uma hora para outra, uma redução de custo modifica todo o relacionamento fornecedor/cliente. Outros problemas relacionados são o desentendimento entre os sócios, os custos elevados, problemas particulares e falta de lucro. Excetuando-se os problemas particulares, todos os outros demandam ajustes na área de administração e de planejamento.

Segundo pesquisas do SEBRAE (2011), a taxa de mortalidade de empresas de micro e pequeno porte é extremamente alta: $75 \%$. Alguns problemas que afetam o comportamento dos microempreendimentos e concorrem para o fechamento de seus negócios são:

$58 \%$ dos empresários que fecharam seus negócios não sabiam que ter uma equipe treinada e qualificada era importante.

$53 \%$ não sabiam quem e quais eram seus clientes.

49\% desconheciam o número de concorrentes.

$47 \%$ não acreditavam que a localização era importante.

$42 \%$ desconheciam as bases legais e jurídicas de seu negócio.

$38 \%$ não conheciam quem eram seus fornecedores.

$36 \%$ não sabiam o valor investido inicialmente em seu negócio.

Em vista disso, o empreendedor torna-se fator primordial do sucesso e do fracasso do próprio negócio. Se não contar com ajuda para capacitação e treinamentos próprios, dificilmente seu negócio irá prosperar.

Santos e Pereira (1995) também apontam fatores que levam um empreendimento ao fracasso:

a) Falta de experiência empresarial anterior.

b) Falta de competência gerencial.

c) Desconhecimento do mercado.

d) Desconhecimento do produto ou serviço.

e) Falta de qualidade nos produtos ou serviços.

f) Localização errada do imóvel e do ponto.

g) Problemas na relação com fornecedores.

h) Tecnologia de produção obsoleta e ultrapassada.

i) Imobilização dos ativos. 
j) Política equivocada de créditos aos clientes.

k) Falta de controles de custos e de gestão financeira.

1) Estrutura inadequada.

m) Falta de planejamento e informações gerenciais.

n) Ausência de inovação gerencial.

\section{METODOLOGIA E ANÁLISE DA PESQUISA APLICADA}

No sentido de encontrar as respostas para as dificuldades superadas pelos pequenos empreendedores nos setores de produtos e serviços das regiões oeste e norte da capital de São Paulo, seis empresas estabelecidas nessas regiões foram analisadas. Antes, foi feito um contato para verificar os anos destas empresas no mercado e se estas consentiriam em participar de uma pesquisa. A pesquisa foi efetuada no mês de julho de 2014.

A pesquisa qualitativa foi realizada por meio de uma amostra não probabilística por cota, com perguntas preestabelecidas e entrevistas pessoais em profundidade. Isso porque, segundo Boni et al. (2005), "em certo momento da pesquisa, o objetivo do pesquisador é conseguir informações ou coletar dados que não seriam possíveis somente através da pesquisa bibliográfica e da observação. Uma das formas que complementam estas coletas é a entrevista".

Já a entrevista é definida por Haguette (1997 apud Boni et al., 2005) como um "processo de interação social entre duas pessoas na qual uma delas, o entrevistador, tem por objetivo a obtenção de informações por parte do outro, o entrevistado”.

Como relatam Boni et al. (2005), "a entrevista como coleta de dados sobre um determinado tema científico é uma técnica muito utilizada no processo de trabalho de campo. Através dela, os pesquisadores buscam obter informações ou coletar dados objetivos e subjetivos".

Para a preparação da entrevista, foi elaborado um roteiro e este foi aplicado a todos os respondentes, para a possibilidade de comparação entre as respostas (LODI, 1974 apud BONI et al., 2005).

Para elaboração do roteiro em si, foi utilizado o resultado apurado pelo SEBRAE (2010), com as principais dificuldades enfrentadas pelos empreendedores no primeiro ano de atividade, e, segundo Santos e Pereira (1995), com os fatores que levam um empreendimento ao fracasso, que são: 
1) Falta de clientes.

2) Falta de capital.

3) Problemas com administração e planejamento.

4) Burocracia e impostos.

5) Desconhecimento do mercado.

6) Localização errada do imóvel ou do ponto.

7) Problemas com fornecedores.

8) Falta de controle de custos e gestão financeira.

9) Estrutura inadequada.

\subsection{Análise da pesquisa aplicada}

No Brasil, de acordo com as pesquisas do SEBRAE (2010), 75\% dos negócios que abrem, fecham nos primeiros seis meses de existência, sendo que 25\% sobrevivem e ganham estabilidade no mercado.

No sentido de procurar respostas do por que alguns negócios sobrevivem e passam ao largo das dificuldades iniciais de um novo empreendimento, foram convidadas a participar desta pesquisa seis empresas das zonas oeste e norte da capital paulista (três da zona norte e três da zona oeste). Estes locais foram escolhidos pela proximidade dos terminais dos metrôs Santana e Butantã, o que, teoricamente, acarreta enorme fluxo de pessoas. Estas empresas estão há mais de cinco anos no nicho de mercado em que atuam: vendas e comércio de brindes, comércio e serviços de manutenção de impressoras de grande porte, impressão em silk screen, comércio de papelaria, digitalização e editoração eletrônica e fotografia e empresa de eventos corporativos, sendo duas MEI e quatro EPP (microempreendedor individual e empresa de pequeno porte, respectivamente).

As entrevistas foram realizadas nos próprios estabelecimentos em que os empreendedores atuam e, para auxiliar na busca de resultados, nove temas foram abordados, seguindo os critérios já mencionados.

\subsection{Análise comparativa das respostas}

Item 1 - Falta de clientes

Sobre este tema, as opiniões dos entrevistados convergem num ponto crucial. Todos eles responderam que, de uma forma ou de outra, ou o próprio empreendedor ou o sócio atuou anteriormente como empregado nos segmentos que optaram por abrir um negócio. $\mathrm{O}$ 
conhecimento de fornecedores, agências e clientes em potencial adquirido quando empregados ajudou sobremaneira na formação de uma carteira de clientes, e as ferramentas de marketing complementaram a visibilidade dos negócios e sua continuidade. A fidelização do cliente, com produtos de qualidade, prazos e preços, alavancou os empreendimentos.

\section{Item 2 - Falta de capital}

A falta de capital realmente é um problema que todos os empreendedores enfrentam quando da composição de seu negócio. Conforme pesquisas do SEBRAE (2010), os empreendimentos são abertos pela necessidade, não pela oportunidade de um plano de negócios bem-sucedido. Antes de montar seu próprio negócio, o empreendedor desconhece detalhes daquilo que pretende apresentar e, nos primeiros seis meses, aprende ou não. Se não conseguiu integrar-se, fecha. Todos os entrevistados levaram o "susto inicial" de falta de capital de giro para atender as suas necessidades. A solução encontrada foi captar dinheiro em bancos ou apresentar projetos ao BNDES ou PROGER, além da venda de ativos, tais como automóveis e apartamentos para sobreviver. $\mathrm{O}$ empreendedor de impressoras de grande porte optou por fazer um bom estoque de peças de reposição, auxiliado pelo cliente multinacional para o qual presta serviços. A permuta também é uma forma de fazer frente à falta de capital; a troca de mercadorias e serviços sem o uso de moeda permite o trabalho sem sobressaltos e atualização de seu negócio.

Item 3 - Problemas na administração e no planejamento

Várias soluções foram apresentadas para este tópico. O auxílio de um contador, até que o empreendedor tivesse certeza do que iria fazer na administração, foi importante. Depois, o próprio empreendedor determina sua forma de atuação, no sentido de estabelecer controles, seja por meio de planilhas eletrônicas, seja por meio de sofisticados softwares de gerenciamento de negócios. A divisão do trabalho entre três sócios, cada qual se ocupando de uma determinada frente também foi um ponto importante, pois não sobrecarrega ninguém.

A ajuda do SEBRAE também foi apontada como ponto-chave. Este órgão atua dando consultoria, treinamento e suporte para o empreendedor.

\section{Item 4 - Burocracia e impostos}

Todos os entrevistados contaram com a ajuda de um contador ou de um escritório de contabilidade para resolver os problemas da burocracia estatal e da apuração dos impostos. Hoje o governo tem o SIMPLES, aparentemente como simplificador da gestão dos impostos e 
taxas pelos empresários, mas, na opinião dos gestores, as mudanças sem aviso são um grande empecilho para se entender as normas existentes na legislação. A busca de informação só é conseguida quando o empreendedor erra, sendo glosado e autuado. Na opinião de alguns, essa legislação necessita de um tributarista para entendê-la e segui-la, coisa que só pode ser feita por um escritório de contabilidade. Essa ajuda possibilita o pagamento correto dos impostos e das obrigações. Tira o empreendedor desse foco e permite que ele possa cuidar de sua empresa.

Item 5 - Desconhecimento de mercado

Como no primeiro item, este também apresenta convergência entre os entrevistados. O empreendedor já participava antes como empregado do segmento em que optou por montar uma empresa. Já tinha uma experiência, ainda que de empregado, mas que possibilitava o conhecimento, a forma de atuação e a apresentação, como um todo, do cenário em que iria envolver-se no futuro. Nenhum deles foi um desbravador ou um inovador apresentando uma ideia ou uma proposta nova de trabalho. Seguiram apenas com aquilo que já conheciam. O conhecimento do mercado e de sua volatilidade possibilitou ao empreendedor um início sem muitos sobressaltos.

Item 6 - Localização errada do imóvel ou do ponto

Todos os empreendedores, exceto a empreendedora que possui uma papelaria, entendem que a localização do ponto ou do imóvel não foi e não é importante. O ponto ou o imóvel é apenas um local em que muito eventualmente vão receber clientes, é onde os empreendedores vão cuidar da produção, do marketing, dos telefonemas, da internet. Tanto é assim que um deles abriu seu empreendimento na própria casa, e tem um horário até que flexível, mas sem hora para começar nem para fechar. Os telefones e os computadores ficam conectados o tempo todo. A lojista tem uma papelaria aberta em frente a um shopping e considera o ponto muito bom para um empreendimento de portas abertas. $\mathrm{O}$ fluxo de pessoas é favorável, assim como a localização.

Item 7 - Problemas com fornecedores

De uma maneira geral, todos esses empreendedores já conheciam ou pelo menos já sabiam da existência de seus fornecedores ao abrir seu negócio. Pelo longo contato tornaramse parceiros, não apresentando problemas. A empreendedora de brindes justifica que, se o fornecedor apresentar problemas, troca, mas também não teve ou tem problemas com 
fornecedores nacionais. Sua principal reclamação é em relação ao fornecedor estrangeiro, principalmente o chinês, que costumeiramente impacta o negócio com problemas de notas fiscais, códigos tributários, prazos e preços.

Item 8 - Falta de controle de custos e gestão financeira

Para superar as dificuldades iniciais, o escritório de contabilidade faz sua parte auxiliando o empreendedor. O tipo de negócio com que se trabalha, como, por exemplo, impressoras, cujos preços de peças de reposição são controlados pelo fabricante, dá um norte um pouco diferente. O empreendedor, nesse caso, precisa apenas acrescentar sua margem de lucro ao negócio. O preço da mão de obra é o mercado que estabelece, pois todas as empresas do segmento de impressoras têm preços mais ou menos no mesmo patamar. Para aqueles empreendedores que trabalham com produção, a pessoa que faz as compras, a cotação e os orçamentos é quem cuida da administração financeira, sabendo tudo o que entra, tudo o que sai, toda a composição dos custos industriais e entrada e saída de dinheiro. Na maioria das respostas, foi verificado que os empreendedores, além de contabilista, contavam com controladores de custos. Falou-se também, em duas respostas, de um software de gestão negócio de pequeno porte como facilitador deste tipo de operação.

\section{Item 9 - Estrutura inadequada}

Todas as respostas apresentaram que a estrutura é, e sempre foi, adequada, tendo variado ao longo do tempo, dependendo do avanço ou retrocesso do negócio. Quando necessário, há a admissão de freelancers, sendo estes dispensados quando a produção é normalizada. Os empreendedores trabalham com a estrutura de acordo com o tamanho do negócio, se precisa crescer, melhora-se; se está em crise, volta-se para o patamar original. Em resumo, é a aceitação no mercado e a solicitação do mercado que provocam alterações na estrutura original de um negócio.

\section{CONSIDERAÇÕES FINAIS}

Este trabalho analisou, por meio de entrevistas pessoais em profundidade, a situação de seis empresas empreendedoras com mais de cinco anos no mercado, e, como tal, livres do ambiente de mortalidade dos seis meses. Tais empresas atuam em diversos segmentos da economia e do mercado. Esta pesquisa se baseou em nove fatores apontados pelo SEBRAE (2010) e por Santos e Pereira (1995) como motivos de fechamento dos pequenos negócios.

ReFAE - Revista da Faculdade de Administração e Economia, v. 8, n. 2, p. 189-208, 2017 
Verificando as respostas dos empreendedores, foi constatado que estes, ao criar suas empresas, não fizeram nada de inovador. Não se "jogaram numa aventura". Todos, de uma forma ou de outra, como empregado ou empregador, conheciam o nicho de mercado em que pretendiam atuar. A captação de clientes para o novo negócio foi simplificada pelo conhecimento e pelo network adquirido. Com a qualidade do atendimento apresentado e usando internet e sites, conseguiram novos clientes e aceitação no mercado. $\mathbf{O}$ ponto ou imóvel, na maioria das respostas, não foi e não é importante para esses empreendedores. Para todos eles, o local é apenas para referência, excetuando-se a lojista, que, por ser um comércio, necessita de um ponto apropriado para atender os clientes.

A falta de capital também não foi impedimento para esses empreendedores. Ao término do capital inicial, com o surgimento de novas despesas, não percebidas quando da inauguração, buscaram empréstimos bancários, ajuda de empresas especializadas e projetos. Cursos, treinamentos no SEBRAE, software de gerenciamento foram alavancas positivas para eles. Acrescenta-se também a persistência, sempre necessária na busca de objetivos.

$\mathrm{O}$ apoio de contadores e de boas empresas de contabilidade foram aspectos positivos no começo da gestão. Os empresários não se fixaram na burocracia estatal e na burocracia dos impostos. Se não conseguiam entender o Simples Nacional, os contadores resolviam a questão. A busca de informações com empresários ou pessoas experientes também foi positiva.

A divisão do trabalho e a gestão de custos e a gestão financeira nas mãos de uma só pessoa proporcionou mais segurança a estes empresários. Pelo conhecimento adquirido anteriormente e pela continuidade, a ligação com fornecedores tornou-se estreita, motivo pelo qual não apresentou problemas.

Outro fator digno de relato é a estrutura. O mercado é "um termômetro" para aumentar ou diminuir a estrutura de um empreendimento. Se o mercado é favorável, ele é aumentado; se está em crise, é estabilizado ou diminuído. Por isso, os empreendedores não tiveram problemas com a adequação da estrutura do negócio.

Levando-se em conta tudo isso, podemos dizer que essas foram atitudes que deram força e equilíbrio aos empreendedores e fizeram com que atingissem o ponto da estabilidade. Atitudes que eventualmente não foram tomadas por aqueles cujos negócios declinaram nos primeiros meses de existência.

No tocante à administração e ao planejamento dos empreendimentos, assim como em relação aos impostos, os empreendedores tiveram e têm a ajuda de um escritório de contabilidade e de um contador. Inicialmente executando todo o trabalho, e, à medida do ReFAE - Revista da Faculdade de Administração e Economia, v. 8, n. 2, p. 189-208, 2017 
possível, passando e treinando os empreendedores, que depois ficariam com essa responsabilidade.

Consideramos que este trabalho constitui um pequeno passo para a compreensão do quadro exposto, e que pretendeu contribuir para as pesquisas sequenciais da área.

Em um país como o Brasil, carente ainda de igualdade de oportunidades, os microempreendedores que conseguiram sobreviver às barreiras e aos desafios do mercado podem se tornar benchmark para os que estão dando ainda um primeiro passo no empreendedorismo.

\section{REFERENCIAS}

AGÊNCIA BRASIL. Disponível em: <http://agenciabrasil.ebc.com.br/noticia/2013-1004/marco-entre-ditadura-e-democracia-constituicao-de-1988-completa-25-anos>, acessado em: 27 de novembro de 2013 às 10 h45.

ANVISA.

Disponível

em: $<$ http://portal.anvisa.gov.br/wps/content/Anvisa+Portal/Anvisa/Inicio/Alimentos/Assuntos+de +Interesse/Legislacao/Legislacao+Geral>, acessado em: 24 de fevereiro de 2014 às $11 \mathrm{~h} 00$.

BERNARDI, Luiz A. Manual de Plano de Negócios. São Paulo: Atlas, 2006.

BONI, V.; QUARESMA, J. Aprendendo a entrevistar: Como fazer entrevistas em Ciências Sociais, Revista Eletrônica dos Pós Graduandos em Sociologia Política da UFSC, vol. 2 $n^{\text {o }} 1(13)$, janeiro/julho/2005, p.68-80.

CALDAS, GILBERTO. Nova Constituição Brasileira. 2a Ed. São Paulo: Livraria e Editora Universitária de Direito, 1989.

ENCARGOS de mão de obra, abertura de uma empresa. Disponível em: <http://www.contabilidadenelma.com.br>, acessado em: 8 de julho de 2007.

FERNANDO, L. et al. Fatores Associados à Mortalidade Precoce de Micro e Pequenas Empresas da Cidade de São Paulo. ENANPAD, R.J., p. 1-16, set. 2004.

FIGUEIREDO, Odail. 40 anos acreditando. RUMOS - n³1 - Novembro/Dezembro, 2012. SEBRAE. 
FLEURY, Afonso C.C. Competências essenciais, perspectivas para internacionalização de empresas no Brasil. Revista Gestão e Produção. v.10, n.2, p.129-144, ago. 2003.

FUKELMAN, C., Lima Patrícia S. Artes de Sobrevivência em ofícios ambulantes, artigo disponível em: <http://www.mao.com.br/novo/pdf/fukelman_01.pdf> acessado em: 8 de outubro de 2012 às $17 \mathrm{~h} 00$.

LIMA, M. V. A. ET AL. Avaliação Multi Critério do risco percebido de falência das micro e pequenas empresas brasileiras. Revista da Micro e pequena empresa, Campo Limpo Paulista, p. 111-126, 2010.

MINISTÉRIO DO COMÉRCO EXTERIOR. Página Brasileira do Ministério do Comércio Exterior no MERCOSUL. Disponível em: <http://www.mercosul.gov.br>, acessado em: 27 de novembro de 2013 às $12 \mathrm{~h} 45$.

PASSETTI, G. Interligando a Colônia. A ação dos tropeiros no Brasil dos Séculos XVIII e XIX. Artigo disponível em: <http://www.klepsidra.net/klepsidra4/tropeiros.html>, acessado em: 8 de outubro de 2012 às 17 h00.

PELISSARI, ANDERSON SONCINI. O perfil de qualificação profissional dos empresários das pequenas empresas do ramo de confecção da Glória, Vila Velha, ES. 2002. Dissertação de Mestrado em Engenharia de Produção, UFSC/EPS - UNIVERSIDADE FEDERAL DE SANTA CATARINA. Programa de pós-graduação em Engenharia de Produção. Disponível em: <https://repositorio.ufsc.br>, acessado em: 27 de novembro de 2013 , às 13 h39.

SANTOS, F. A. et al. Contabilidade com ênfase em micro, pequenas e médias empresas. 2a. Ed. São Paulo: Atlas, 2012.

SANTOS, S. A.; PEREIRA, H. J. Criando seu próprio negócio: como desenvolver o potencial empreendedor. Brasília: Ed. SEBRAE, 1995.

SEBRAE. Anuário do Trabalho na Micro e Pequena Empresa 2011 Disponível em: $<$ http://www.sebrae.com.br>, acessado em: 12 de setembro de 2012, às 13 h00.

SEBRAE. BIBLIOTECA. Disponível em: <http://www.sebrae.com.br>. 
SEBRAE. 12 anos de monitoramento da sobrevivência e mortalidade das empresas (agosto de 2010). Disponível em: <http://www.sebrae.com.br $>$, acessado em: 12 de setembro de 2012, às 13 h00.

SEBRAE. 7 passos para abrir uma empresa. Disponível em: <http://www.sebraers.com.br>. Acessado em: 13 de maio de 2014, às 20h00.

SOUZA, Jose H.et al. As origens da micro empresa no Brasil. Revista da Micro e Pequena Empresa. Campo Limpo Paulista, v.1,n.1,p.53-65,2007.

TERENCE, Ana C.F. Elaboração do planejamento estratégico: Estudo e aplicação de um roteiro em pequenas empresas. Revista da Micro e Pequena Empresa. Campo Limpo Paulista, v.1,n.2, p.34-50, 2007.

YAZIGI, Marcos F. Como definir o preço de venda no comércio. SEBRAE, 2001.

ZAMBERLAN, Luciano. Pesquisa de mercado. Coleção Educação à Distância, Série LivroTexto, UNIVERSIDADE REGIONAL DO NOROESTE DO ESTADO DO RIO GRANDE DO SUL - UNIJUÍ, Ijuí, Rio Grande do Sul, Brasil, 2008. 